\title{
A Possible Role of Alkali Metal lons in the Synthesis of Pure-silica Molecular Sieves
}

\author{
Michelle Goepper, Hong-Xin Li and Mark E. Davis* \\ Department of Chemical Engineering, California Institute of Technology, Pasadena, CA 91125, USA
}

Pure-silica ZSM-12 is synthesized in the presence and absence of alkali metal ions; addition of alkali metal ions at constant hydroxide ion concentration increases the crystallization rate of ZSM-12, and it is suggested that alkali metal ions participate in both the nucleation and crystal growth processes.

Organic molecules have been used in the synthesis of aluminosilicate, pure-silica and aluminophosphate molecular sieves. ${ }^{1}$ These species are speculated to act as structuredirecting agents and as space-filling entities. Structure-direction implies that a specific molecular sieve is synthesized from a single organic species. For example, ZSM-18 can be synthesized using only a triply charged triquat cation that may be responsible for specifically templating this unusual structure. ${ }^{2}$ On the other hand, organic species can fill the void spaces of molecular sieves to increase the thermodynamic stability of the composite material over that of the inorganic portion alone. For example, over 20 different organic species can be used in the synthesis of ZSM-5 and $\mathrm{AlPO}_{4}-5$.

When synthesizing aluminosilicate and pure-silica molecular sieves, alkali metal cations are typically used in combination with organic species. The alkali metal cations can serve as the source of hydroxide ions (alkali metal hydroxides) and as framework-charge-balancing ions (for aluminosilicates). Since pure-silica molecular sieves do not require charge balance and the organic species can serve as sources of hydroxide ions, e.g.. quaternary ammonium hydroxides, the role of alkali metal cations in the synthesis of pure-silica molecular sieves remains unclear.

Pure-silica ZSM-5 and ZSM-11 can be synthesized in approximately one week or less in the absence of alkali metal ions. However, most pure-silica molecular sieves require the use of alkali metal ions for their rapid synthesis, e.g. ZSM-12, ZSM-48, SSZ-24, ZSM-35. Gies and Marler ${ }^{3}$ have synthesized a variety of pure-silica clathrasils and molecular sieves from silica, water and organic species, e.g. ZSM-5, ZSM-11, ZSM-48, ZSM-12, ZSM-35. In several cases, the crystallization times were quite long with some lasting up to six months.

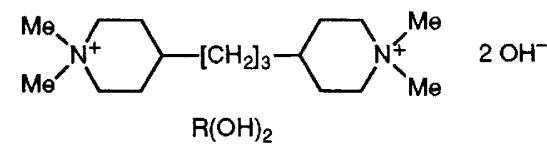

Thus, it appears that alkali metal ions are not necessary for the synthesis of pure-silica molecular sieves, but they may play a role in increasing the kinetics of the crystallization process. Here we suggest that alkali metal ions do participate in the crystallization process by accelerating the rate of crystallization.

We synthesized pure-silica ZSM-12 using 4,4'-trimethylenebis(dimethylpiperidinium) hydroxide ${ }^{4}$ denoted here as $\mathrm{R}(\mathrm{OH})_{2}$. In order to ensure that no alkali metal ions are present in the organic solution, the hydroxide form of the organic species was obtained by the reaction of the iodide form with silver oxide [yielding $\mathrm{R}(\mathrm{OH})_{2}$ and $\mathrm{AgI}$ ].

Table 1 shows the compositions of the reaction mixtures used in this study and the results obtained when heating these mixtures at $150^{\circ} \mathrm{C}$ in unagitated autoclaves at autogenous pressure. The results from experiments $\mathrm{A}-\mathrm{D}$ indicate that $\mathrm{K}^{+}$

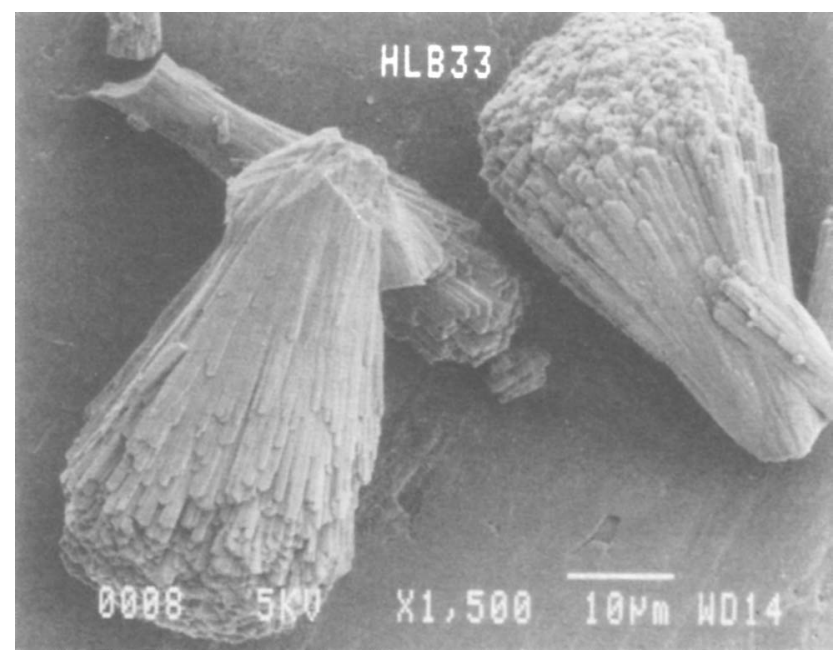

Fig. 1 Scanning electron micrograph of ZSM-12 synthesized without alkali metal ions

Table 1 Crystallization of ZSM- 12 at $150^{\circ} \mathrm{C}$

\begin{tabular}{|c|c|c|c|c|c|c|c|}
\hline \multirow[b]{2}{*}{ Experiment } & \multicolumn{4}{|c|}{ Reactant ratio } & \multirow[b]{2}{*}{ Silica source } & \multirow[b]{2}{*}{$t /$ day } & \multirow[b]{2}{*}{ Result } \\
\hline & $\mathrm{X}^{a} / \mathrm{SiO}_{2}$ & $\mathrm{M}^{+} / \mathrm{SiO}_{2}$ & $\mathrm{OH}^{-} / \mathrm{SiO}_{2}$ & $\mathrm{H}_{2} \mathrm{O} / \mathrm{SiO}_{2}$ & & & \\
\hline A & 0.06 & $0.3(\mathrm{KOH})^{b}$ & 0.42 & 32 & Ludox-AS40 & 7 & ZSM-12 \\
\hline B & 0.16 & $0.1(\mathrm{KOH})$ & 0.42 & 32 & Ludox-AS40 & 7 & ZSM-12 + trace unknown ${ }^{c}$ \\
\hline $\mathrm{C}$ & 0.21 & 0 & 0.42 & 32 & Ludox-AS40 & 17 & Unknown \\
\hline $\mathrm{D}$ & 0.21 & $0.3\left(\mathrm{KNO}_{3}\right)$ & 0.42 & 32 & Ludox-AS40 & 7 & ZSM-12 \\
\hline E & 0.06 & $0.3\left(\mathrm{KNO}_{3}\right)$ & 0.12 & 32 & Ludox-AS40 & 7 & ZSM-12 \\
\hline F & 0.06 & 0 & 0.12 & 30 & Ludox-AS40 & 7 & Unknown ${ }^{c}$ \\
\hline G & 0.06 & 0 & 0.12 & 30 & Ludox-AS40 & 27 & ZSM-12 + unknown ${ }^{c}$ \\
\hline $\mathrm{H}$ & 0.06 & 0 & 0.12 & 30 & Ludox-AS40 & 44 & ZSM-12 \\
\hline I & 0.06 & 0 & 0.12 & 30 & $\begin{array}{l}\text { Ludox-AS40 + } \\
2 \mathrm{wt} \% \text { ZSM-12 seeds }\end{array}$ & 14 & ZSM-12 \\
\hline $\mathrm{J}$ & 0.06 & $0.3(\mathrm{NaOH})$ & 0.42 & 32 & Cab-O-Sil & 7 & ZSM-12 \\
\hline K & 0.06 & $0.3\left(\mathrm{NaNO}_{3}\right)$ & 0.12 & 32 & Cab-O-Sil & 7 & ZSM-12 \\
\hline $\mathrm{L}$ & 0.06 & $0.3\left(\mathrm{NH}_{4} \mathrm{OH}\right)$ & 0.42 & 32 & Cab-O-Sil & 14 & Amorphous \\
\hline M & 0.06 & 0 & 0.12 & 32 & Cab-O-Sil & 84 & ZSM-12 \\
\hline
\end{tabular}

${ }^{a} \mathrm{X}=4,4^{\prime}$-trimethylenebis(dimethylpiperidinium) hydroxide, $\mathrm{R}(\mathrm{OH})_{2} .{ }^{b}$ Source of $\mathrm{M}^{+}$ions. ${ }^{c}$ Most likely a layered silicon dioxide. 
ions are necessary to crystallize pure-silica ZSM-12 (product identification by X-ray powder diffraction) in 7 days. In this set of experiments the $\mathrm{K}^{+}$concentration is varied independently of the $\mathrm{OH}^{-}$concentration. Experiments $\mathrm{F}-\mathrm{H}$ show that $\mathrm{KOH}$ is not necessary for the synthesis of pure-silica ZSM-12. However, at constant hydroxide ion concentration (experiments $\mathrm{E}-\mathrm{H}$ ), the rate of crystallization of ZSM-12 declines as $\mathrm{K}^{+} / \mathrm{SiO}_{2}$ decreases from 0.3 to 0 .

Pure ZSM-12 is obtained in 14 days at $150{ }^{\circ} \mathrm{C}$ in the absence of $\mathrm{K}^{+}$using seed crystals (experiment I). $2 \mathrm{wt} \%$ of the total $\mathrm{SiO}_{2}$ in the reaction mixture is added as uncalcined ZSM-12 (contains R) that serves as seeds for the crystallization process. The addition of seed crystals is normally thought to assist the nucleation process alone. If the $\mathrm{K}^{+}$ions that are added to the reaction mixture participated only in nucleation processes, then the results from experiments $E$ and I should be similar. Since they are not, the potassium ions must participate in both the nucleation and crystal growth processes.

Finally, in order to eliminate all cations (Ludox AS-40 contains ammonium ions) other than the organic species, fumed silica (Cab-O-Sil) is used as the silica source in experiments J-M. ZSM-12 is obtained in 7 days when the reaction mixture contains sodium ions. If no alkali metal ions are added, the crystallization of ZSM- 12 requires $2 \frac{1}{2}$ months. Thus, experiments $\mathrm{J}-\mathrm{M}$ clearly show that $\mathrm{Na}^{+}$ions increase the rate of crystallization of pure-silica ZSM-12 while ammonium ions do not.

All the ZSM-12 samples synthesized in the presence of $\mathrm{Na}^{+}$ or $\mathrm{K}^{+}$have long-grain-like morphology $(\mathrm{ca} .2 .5 \times 0.7 \mu \mathrm{m})$ similar to that illustrated previously for ZSM-12,5 while crystallization without alkali metal ions (experiment $\mathrm{M}$ ) reveals large aggregated needle-like crystals approximately 40 $\mu \mathrm{m}$ in length (see Fig. 1). This again indicates that alkali metal ions play a role in both nucleation and crystal growth processes.

There is experimental evidence to suggest that the rate of crystallization of other pure-silica molecular sieves, e.g. SSZ-24 and ZSM-48, is also increased by the addition of alkali metal ions. Thus, we do not believe this effect is unique to the synthesis of ZSM-12. (At this time, it remains unclear why pure-silica ZSM-5 and ZSM-11 rapidly crystallize in the absence of alkali metal ions.) Since $\mathrm{Si}_{-} \mathrm{O}^{-}$species exist during the crystallization process, it is not unreasonable to suggest that the alkali metal ions $\left(\mathrm{M}^{+}\right)$play a role in the crystallization process by interacting with these groups, e.g. $\mathrm{Si}-\mathrm{O}^{-}\left(\mathrm{M}^{+}\right)$. This interaction would cease upon condensation of the silica species into the growing crystal since all the oxygens bridge two silicon atoms in a fully connected structure (except at defect sites). Once released, the alkali metal ions could again perform this function with other silicate species. Further study is necessary to prove this hypothesis.

Received, 25th June 1992; Com. 2/03352F

\section{References}

1 B. M. Lok, T. R. Cannan and C. A. Messina, Zeolites, 1983, 3, 282.

2 S. L. Lawton and W. J. Rohrbaugh, Science, 1990, 247, 1319.

3 H. Gies and B. Marler, Zeolites, 1992, 12, 42.

4 E. W. Valyocsik, US Pat., 1985, 4539193.

5 S. Ernst, P. A. Jacobs, J. A. Martens and J. Weitkamp, Zeolites, $1987,7,458$. 